\title{
Involvement of F-box proteins in esophageal cancer (Review)
}

\author{
JIAN GONG ${ }^{1}$, ZHENG HUANG $^{2}$ and JI-RONG HUO ${ }^{1}$ \\ ${ }^{1}$ Department of Gastroenterology, The Second Xiangya Hospital, Central South University, \\ Changsha, Hunan 410011; ${ }^{2}$ Department of Spine Surgery, Shenzhen Nanshan Hospital \\ of Guangdong Medical College, Shenzhen, Guangdong 510282, P.R. China
}

Received October 25, 2015; Accepted December 7, 2015

DOI: $10.3892 /$ ijo.2016.3325

\begin{abstract}
The F-box proteins (FBPs) in esophageal tumorigenesis are pivotal as they govern a broad array of basic physiological responses including cell growth, cell death and DNA damage repair. Esophageal cancer (EC) is a common and highly aggressive cancer worldwide. Aberrant stabilization of crucial proteins participates in esophageal tumorigenesis. Recently, growing evidence has shown that FBPs play a critical role in oncogenesis, invasion, metastasis and prognosis assessment of EC. In this review we summarized published data on the roles of known FBPs, their respective substrates and the key signaling pathways, in the development of EC, aiming to uncover new ways for the rational design of targeted therapies in EC.
\end{abstract}

\section{Contents}

1. Brief introduction to esophageal cancer

2. The ubiquitin-proteasome system

3. The F-box proteins

4. The emerging roles of $\mathrm{SCF}^{\mathrm{skp} 2} \mathrm{E} 3$ ligases in $\mathrm{EC}$

5. The emerging roles of $\mathrm{SCF}^{\mathrm{FBXW} 7} \mathrm{E} 3$ ligases in $\mathrm{EC}$

6 . Other FBPs $(\beta$-TrCP, FBXL19, FBXO4, FBXO31 and FBXO32) involved in EC

7. Conclusion and future direction

\section{Brief introduction to EC}

Esophageal cancer is the sixth leading cause of cancer-related mortality and the eighth most common cancer with more than 455,800 new esophageal cancer cases and 400,200 deaths

Correspondence to: Professor Ji-Rong Huo, Department of Gastroenterology, The Second Xiangya Hospital, Central South University, No. 139 Middle Renmin Road, Changsha, Hunan 410011, P.R. China

E-mail:huojir008@126.com

Key words: esophageal cancer, F-box protein, ubiquitin-proteasome system, E3 ubiquitin ligase, SKP2, FBXW7 according to global cancer statistics (1). The incidence rates of EC have been increasing (2). Tobacco use and alcohol consumption are the main risks for EC (3). The two main types of EC are squamous cell carcinoma (SCC) and adenocarcinoma. In the highest-risk area, which stretches from Northern Iran through the Central Asian republics to North-Central China, $90 \%$ of cases are squamous cell carcinomas (4). Despite many advances in EC treatment, over the last several decades, the prognosis for patients with advanced EC remains poor. The overall 5-year survival ranges from $15 \%$ to $25 \%$ (5). Poor outcomes in patients with EC are related to diagnosis at advanced (metastatic or disseminated) stages. New treatment methods and strategies are necessary. Genome instability with alterations in the expression of proteins is a hallmark of cancer (6). Extensive study in this field has led to a better understanding of the molecular mechanism by which FBPs regulate cellular processes and of how their deregulations contribute to carcinogenesis. In this review, we summarize the related FBPs involved in EC, focusing on the function and the substrates of each related F-box protein in EC.

\section{The ubiquitin-proteasome system}

Intracellular protein degradation plays an important role in the regulation of the cell cycle, signal transduction, and disposal of improperly folded proteins. The ubiquitin-proteasome pathway is the major system for protein degradation (7). Ubiquitin Proteasome System (UPS) is an evolutionary conserved protein degradation mechanism that is involved in various physiological responses such as cell cycle control, DNA replication, transcription, and cell signaling $(8,9)$. Ubiquitin (Ub) is a 76-amino acid protein that is covalently conjugated to a lysine residue in proteins. Similarly to phosphorylation, ubiquitination is reversible and linked to deubiquitination.

Ubiquitin-proteasome pathway. Ubiquitin attachment to substrates is accomplished by the coordinated activity of three enzymes: ubiquitin-activating enzyme (E1), ubiquitin conjugating enzyme (E2), and ubiquitin-protein ligase (E3). The degradation of proteins by the UPS is mainly comprised of three steps. The first step is that $\mathrm{Ub}$ is activated by the E1 enzyme by creation of the thioester linkage between $\mathrm{Ub}$ and the cysteine residues of E1 in an ATP and $\mathrm{Mg}^{2+}$-dependent manner. Then, E2 accepts the activated ubiquitin molecule from E1 and with a help from an E3 ubiquitin ligase transfers 


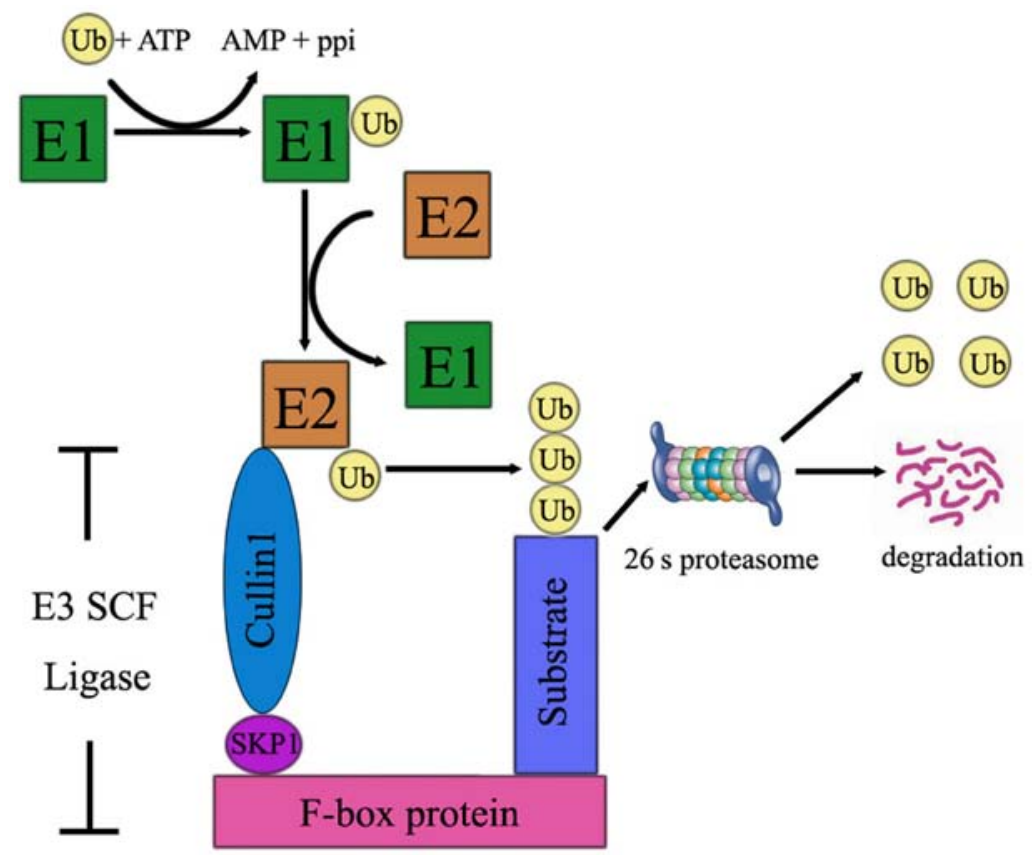

Figure 1. The attachment of ubiquitin to target proteins is mediated by three enzymes: E1,E2,E3. The E1 is the ubiquitin-activating enzyme recruiting ubiquitin . E2 is the ubiquitin-conjugating enzyme that transfers the ubiquitin to the targeted protein. E3 enzymes (ubiquitin ligases) function as the substrate recognition modules of the system and are capable of interaction with both E2 and substrate. Ubiquitin is linked to E1 and activated by using the energy of ATP. The activated ubiquitin is then transferred to E2 ubiquitin-conjugating enzyme. E3 ubiquitin ligase recognizes a protein substrate, recruits an E2-ubiquitin complex, and catalyzes ubiquitin transfer from E2 to substrate. Ubiquitinated proteins can be activated, recognized and degraded by the 26S proteasome. Components of the SCF E3 ubiquitin ligase complex. A scaffold protein Cullin is associated with an adaptor protein (SKP1) and a RING finger protein RBX1(RBX2). F-box protein determines the specificity of the target proteins. CUL-RBX1(RBX2) catalyzes the transfer of the ubiquitin from an E2 to the substrate.

it to the lysine residue of a target protein. In the third step, the ubiquitin proteins are recognized and degraded by 26 proteasome to several small peptides (Fig. 1). Ubiquitin-mediated proteolysis is instigated by the attachment of K48 polyubiquitin chains to substrates, which provides a signal for recognition and degradation by the proteasome. E3 ubiquitin ligases are a large family of proteins that are engaged in the regulation of the turnover and activity of many target proteins. E3 determines the target protein specificity, and it is the reason why the deregulation of E3 ligase often leads to cancer development (10).

Ubiquitin enzymes. Human genome encodes 2 E1s, approximately $30 \mathrm{E} 2 \mathrm{~s}$ and more than $600 \mathrm{E} 3 \mathrm{~s}$ (11). E3 ligases determine the substrate specificity for ubiquitylation and subsequent degradation. The largest family of E3 ubiquitin ligases is the RING type SCF E3 ligases (RING-E3s). RING-E3s can further be subdivided into RING-containing single peptide E3s, Cullin-RING ligases (CRLs) and their derivatives, U-box E3s (11). CRLs complex is the largest family of RING-E3s in the family, which contains eight members: namely CRL1, CRL2, CRL3, CRL4A, CRL4B, CRL5, CRL7 and CRL9. Within the eight CRLs, CRL1 is so far the best-characterized member, which is also designated as the SKP1-cullin 1-F-box protein (SCF). The best characterized of CRLs family E3s is Skp1-Cullin1-F-box (SCF) complex $(12,13)$. All SCF E3 ligases share a similar structure in which CUL binds to SKP1 and an F-box protein at the N-terminus and a RING protein $\mathrm{RBX} 1$ or RBX2 at the C-terminus. SCF complex consists of four structural and functional components: Skp1 (adaptor protein), Cul1, ROC1/Rbx1 (RING protein), and F-box protein, the latter of which serves as a receptor for target proteins.

\section{The F-box protein families}

F-box is a widespread protein motif of $\sim 40-50$ amino acids and it functions as a site of protein-protein interaction. F-box proteins are categorized within three families based on the recognizable domains beyond the F-box domain, which comprise the Leu-rich repeat (L) family, WD40 domain (W) family and the F-box only (O) family (Fig. 2). So far, 69 FBPs were identified in the human genome (14) and newer members of the F-box protein family are being discovered. Extensive studies have been heavily focused on only four FBPs SKP2, FBXW7, $\beta$-TrCP1, $\beta$-TrCP2, and the other FBPs largely remain functionally mysterious.

The FBXW family. The FBXW family is composed of 10 proteins, all the members contain WD40 repeat domains. Proteins involved in protein-protein interaction and containing WD40 repeats comprise the first class of FBPs (FBXWs). There are 10 family members of FBXWs. This class mainly targets proteins involved in cell cycle regulation and tumorigenesis and thereby modulating their outcome. The typical representatives of FBXW family are $\beta \operatorname{TrCP} 1$ (FBXW1), $\beta \operatorname{TrCP} 2$ (FBXW11), hCdc4 (FBXW7). The roles of $\beta$-TrCP in cancer differ according to its substrates. Loss of FBXW7 has been found in many cancers and it is associated with poor prognosis. FBXW4 is mutated, lost and underexpressed in a variety of human cancer cell lines and clinical patient samples (15). FBXW8 is the only known F-box protein to form an E3 complex with Skp1, Rbx1 and Cul7, which does not bind SKP1 alone but selectively interacts with Skp1-FBXW8 heterodimer (16). 


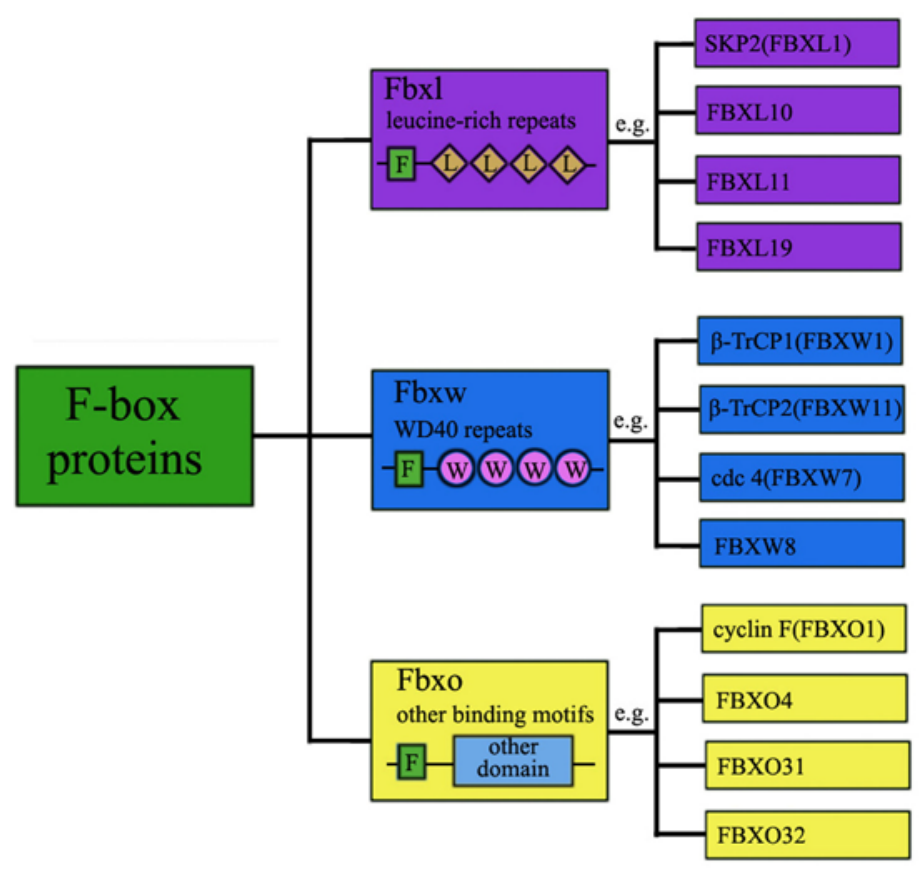

Figure 2. The family of FBPs. In humans, FBPs have been classified into three categories according to their specific substrate recognition domains. FBXL family proteins are those with Leu-rich repeat (LRR) domains. FBXW family proteins are those with WD40 repeat domain-containing domain. The remaining FBPs contain other diverse protein-interaction domains or no recognizable domains, and are called FBXO family proteins.

The FBXL family. Some F-box proteins harbor an F-box and leucine-rich repeats (LRRs). For this reason, the 22 FBPs with LRRs are designated as FBXLs. These motifs are 20-29 residue sequences that are frequent in many proteins providing a structural framework for protein-protein recognition mechanism. SKP2 (also known as FBXL1) can serve as an exemplified family member that has been comprehensively studied and well characterized with respect to its substrates. SKP2 is overexpressed in various types of human cancers, which supports its role as a proto-oncoprotein. FBXL10 overexpression was observed in human pancreatic cancer (17). FBXL5 inhibited the metastasis of gastric cancer (18).

The FBXO family. FBXO proteins do not possess either WD40 or LRR domains, but usually have other protein-protein interaction domains such as zinc-finger, carbohydrate interacting (CASH), proline-rich domains, Sec7, cyclinbox, Traf-domainlike and calponin homology $(\mathrm{CH})(19)$. FBXO family is the most diverse subfamily of FBPs. Those proteins have other different or unknown domain in the $\mathrm{C}$-terminal region. There are 37 members in the FBXO family. Currently, emerging experimental and clinical data have begun to reveal some interesting biological functions on FBXO proteins. FBXO5, an anaphase-promoting complex/cyclosome inhibitor, can control tumor cell proliferation. FBXO5 overexpression causes mitotic catastrophe and genomic instability and potentially contributes to tumorigenesis (20). FBXO11 targets BCL6 for degradation and functions as a tumor suppressor in diffuse large B-cell lymphomas (21).

\section{The emerging roles of $\mathrm{SCF}^{\text {skp2 }} \mathrm{E3}$ ligases in $\mathrm{EC}$}

SKP2, located on 5p13 chromosome, was discovered in 1995 by Beach and his collaborators (22). The $\mathrm{SCF}^{\text {skp2 }} \mathrm{E} 3$ ligase contains at the N-terminus an F-box domain which facilitates its binding to SKP1 and CUL1 and at the C-terminus a leucine-rich repeat domain for substrate recognition. SKP2, $\mathrm{S}$-phase kinase associated protein 2, plays a crucial role in cell cycle progression by promoting the degradation of many key regulatory proteins, including p27, p16, p21, p57, E2F-1, TOB1, RBL2, cyclin D/E, BRCA2, FOXO1, RASSF1A. As the majority of the substrates are tumor supressor proteins, it can be asserted that SKP2 functions as an oncogene (23-26). P27 is a negative regulator of the cell cycle that plays an important role in tumor suppression. Loss of p27 results in uncontrolled proliferation and promotes tumor progression $(20,27)$. Taken together, these findings indicate that the SKP2-mediated reduction, as a result of enhanced degradation of tumor suppressor p27, contribute to the development of cancers including esophageal cancer (28). Therefore, the p27 degradation inhibitors present an attractive target for drugs. The involvement of SKP2 overexpression in metastasis has been reported in many tumors including melanoma (29), nasopharyngeal carcinoma (30), pancreatic cancer (31), breast (32) and colorectal cancer (33). Collectively, these data suggest SKP2 to be a proto-oncoprotein.

The involvement of SKP2 as a common driving factor in carcinogenesis has been proven. Fukuchi et al (24) first elucidated the role of SKP2 in tumor progression, in which they suggested that SKP2 might be a prognostic factor in early stage ESCC. They analyzed SKP2 and p27 expression in surgical specimens obtained from 32 patients, and they found that SKP2 expression showed an inverse location and correlation to p27 expression in early compared to advanced ESCC. There was an inverse relationship between SKP2 and p27 in 6 ESCC cell lines, but not cyclin E, cyclin D1 and E2F-1. DNA amplification is one of the mechanisms activating SKP2 gene in ESCC. Amplification and elevated expression of SKP2 was 
correlated significantly with tumor stage and positive lymph node metastasis in ESCC (34). Downregulation of SKP2 by antisense treatment induced apoptosis and inhibited invasion and migration in lung cancer cells (35). Wang et al (36) found that SKP2 expression levels was increased in ESCC tissues. Elevated expression of SKP2 correlated significantly with tumor stage and positive lymph node metastasis, and high expression of SKP2 promoted the radioresistance of ESCC cancer cells in part through Rad51 pathway. These alterations in the various ways of the carcinogenesis appeared in different stages of EC. The expression of SKP2 protein increased during esophageal squamous cell cancer progression from normal esophageal tissues to esophageal intraepithelial dysplasia (EID) and ESCC, which indicated SKP2 as a potential diagnostic mark in clinical settings (37). Liang et al (38) showed that SKP2 expression was not correlated with lymph node metastasis, but correlated with local tumor invasion, which was not consistent with the observation of Wang et al (36). SKP2 expression might be a new prognostic biomarker for tumor recurrence in ESCC patients.

Molecular mechanisms by which SKP2 induces tumor growth have not been fully elucidated. Some studies on the relationship between PI3K/Akt pathway and SKP2 have been reported. Akt is a downstream molecule of PI3K in response to growth factor stimulation, and activated Akt promotes cell survival by suppressing apoptosis (39). PI3-K/Akt pathway leads to elevated SKP2 expression and subsequent enhanced p27 destruction in human cancers. Inhibition of Akt1 activity in breast cancer cells could downregulate SKP2 expression (40). SKP2 is the main determinant in the PI3K/Akt-dependent regulation of $\mathrm{p} 27$ (kip1) in the prostate cancer cell lines PC3 and DU145 (41). Reichert et al (42) showed that in pancreatic ductal adenocarcinoma cells, PI3K/Akt signaling was linked to SKP2 gene transcription via control of a cis-acting element, $\mathrm{E} 2 \mathrm{~F} 1$, binding to the proximal human SKP2 gene promoter. Whereas, the degradation of E2F1 in S-G2 phase was mediated by $\mathrm{SCF}^{\mathrm{SKP} 2}$ complex (43). Others have also reported that PI3K/Akt signaling controls SKP2 transcription in different cellular systems (44). However, whether SKP2 also can affect the PI3K-Akt pathway still remains unclear. Wang et al (34) showed that decreased SKP2 reduced pAkt expression, and that the PI3K/AKT pathway is the downstream target of SKP2. These results suggest a possible negative feedback loop between PI3K/Akt and SKP2 that may help to maintain the balance between cell survival and apoptosis. Further research exploring the molecular mechanisms by which SKP2 affects the PI3K/Akt pathway awaits further investigation.

\section{The emerging roles of $\mathrm{SCF}^{\mathrm{FBXw7}} \mathrm{E3}$ ligases in EC}

FBXW7, F-box and WD40 repeat domain-containing 7, is an F-box protein that is responsible for substrate recognition by an SCF (Skp1-Cul1-F-box protein)-type ubiquitin ligase complex. FBXW7 was first identified in budding yeast in 1973 (45). FBXW7 is localized to chromosome region 4q32 and has three isoforms (FBXW7 $\alpha$, FBXW7 $\beta$, FBXW7 $\gamma$ ) (46). All three isoforms contain conserved interaction domains in the C-terminus and various isoform-specific domains in the N-terminal region. FBXW7 has pivotal roles in cell division, growth, and differentiation. Burgeoning amounts of literature strongly supported FBXW7 was a tumor suppressor in human cancers based on the following evidence: i) FBXW7 low expression was frequently found in various human cancers (47). ii) FBXW7 mediates the degradation of several major oncoproteins such as cyclin E (48), c-Myc (49), Notch (50) and c-Jun (50), which function in proliferation, differentiation, apoptosis, and metabolism. iii) Decreased FBXW7 protein is associated with poor prognosis as well as tumor metastasis (51-55). iv) FBXW7 $\beta$ is a p53 target gene and p53 mutations may reduce FBXW7 expression (56). Furthermore, loss of FBXW7 in cancer cells might promote resistance to taxol and ABT-737 (57,58). These observations suggest that by upregulating FBXW7, drug resistance could be reversed. It is worth mentioning that most studies focus on discovering the ubiquitin targets of FBXW7 ubiquitin ligase pathway.

Increased number of substrates have deepened our understanding of the diverse oncogenic pathways that FBXW7 regulates. It is widely accepted that the FBXW7 gene mutations and allelic loss are the main mechanisms which downregulate FBXW7 protein expression and its tumor suppressor functions in cancer. Proteasome-mediated FBXW7 protein degradation is another mechanism $(59,60)$. Over the past 5 years, our understanding of the FBXW7 has increased enormously. The first to explore FBXW7 in EC was Sterian et al (61), they found that $54 \%$ of the esophageal adenocarcinomas showed allelic deletion in the chromosome $4 \mathrm{q}$ region. This was confirmed by exome sequencing on 113 ESCC tumor-normal pairs. The link between the expression of FBXW7 protein and prognosis has been verified in many cancers. In ESCC, decreased FBXW7 protein level may contribute to tumor progression and local invasiveness (62). In support of this notion, FBXW7 mRNA was significantly lower in ESCC cancer tissues than in non-cancer tissues, which is correlated with poor prognosis in ESCC (63). RNAi-mediated knockdown of FBXW7 in ESCC cells promotes proliferation in ESCC cell line KYSE70 (63). FBXW7 expression is under the control of several oncogenic micro-RNAs such as miR-27, miR-92, and miR-223 in numerous cancers. Overexpression of miR-223 increases genomic instability by modulating expression of FBXW7 (64). There was a significant inverse relationship between the expression levels of miR-223 and FBXW7 protein in ESCC, which indicated FBXW7 as a functional downstream target of miR-223 (54).

\section{Other FBPs ( $\beta$-TrCP, FBXL19, FBXO4, FBXO31 and FBXO32) involved in EC}

FBPs as tumor suppressors in EC

FBXO32. FBXO32, known as atrogin-1, was firstly discovered by Gomes et al (65) involved in muscle atrophy (66). FBXO32 may be a functional tumor suppressor in cancers. FBXO32 in tumors was significantly lower than that in corresponding normal tissues and it was associated with TNM stage, depth of invasion, distant metastasis or recurrence. While, the methylation frequency of FBXO32 in tumor tissues was significantly greater than that in corresponding normal tissues (67). Overexpressed FBXO32 induces apoptosis of the ESCC cell line TE13 (67). The frequency of FBXO32 methylation in gastric cardia adenocarcinoma (GCA) tumor tissues was significantly higher than that in corresponding normal 
tissues and was associated with TNM stage, pathological differentiation, distant metastasis (68). The methylation status of FBXO32 could predict survival in cancers $(67,69)$. Taken together, aberrant hypermethylation of FBXO32 may be one of the mechanisms that lead to loss, or down regulation of the gene in cancer.

$\beta$-TrCP. Human $\beta$-Transducin repeat-containing protein $(\beta-\operatorname{TrCP})$, first identified in 1998 as a binding partner of HIV-1 $\mathrm{Vpu}$ protein in a yeast two-hybrid screening. The role of $\beta-\operatorname{TrCP}$ in cancers is tissue-dependent. Overexpressed $\beta-\operatorname{TrCP} 1$ or $\beta$-TrCP2 has been detected in multiple cancers, including gastrointestinal cancers, hepato-blastoma, colorectal cancer, pancreatic cancer, breast cancer and melanoma, suggesting a carcinogenic function for these two proteins. $\beta$-TrCP also participates in cell adhesion and migration (70). One typical substrate of $\beta$-TrCP is the IкB protein, the inhibitor of the $\mathrm{NF} \kappa \mathrm{B}$ pathway (71). Another substrate is $\beta$-catenin in Wnt pathway (72). I $\kappa$ B functions as a tumor suppressor. $\beta$-catenin has been identified to be upregulated in various types of human cancer, and is always correlated with poor prognosis and short survival $(73,74)$. IкB and $\beta$-catenin exerting antagonistic functions make it hard to be an ideal drug target. $\beta$-TrCP is a member of the SCF family with both oncogenic and tumor suppressor properties. In most cases, $\beta$-TrCPs function as oncoproteins, whereas in a few others, they have displayed tumor suppressive functions. Studies investigating the role of $\beta-\operatorname{TrCP}$ in esophageal tumorigenesis are limited. Li et al (75) first evaluated the significance of $\beta-\operatorname{TrCP}$ in ESCC. Reduced expression of $\beta$-TrCP was observed in $24.4 \%$ (29/119) ESCC specimens. There was no correlation among the expressions of $\beta$-catenin and $\beta$-TrCP. No correlation between immunoexpression of $\beta-\operatorname{TrCP}$ and clinicopathological parameters was found in ESCC patients (75).

FBXL19. Human FBXL19 (CXXC11) gene was first identified through an in silico search in 2004 (76). FBXL19 is one of the genes related to psoriasis and psoriatic arthritis (77-79). Interleukin-33 (IL-33) is an endogenous proinflammatory danger signal released from injured or dying host cells (80). ST2L, a member of the family of IL-1 receptors, has been identified as the receptor for IL-33. FBXL19 regulates the IL-33-ST2L axis, selectively mediating ST2L for ubiquitination and degradation, to limit IL-33-induced pulmonary inflammation (81). FBXL19 exhibits an anti-tumor property by downregulation of small GTPase. $\mathrm{SCF}^{\mathrm{FBXL} 19}$ may affect cell motility by targeting Rac1 for its ubiquitination and degradation (82). Rac1 (ras-related C3 botulinum toxin substrate 1), a member of the small G-protein Rho family, triggers intracellular signaling such as cell proliferation and cytoskeletal reorganization. Overexpression of FBXL19 reduced both active and inactive forms of Rac1 protein. Inactivation or knockdown of Rac1 significantly reduces the cell migration rate in various cell types $(83,84)$. Rac3 is a small GTPase multifunctional protein that regulates cell adhesion, migration, and differentiation, which has been considered as an oncogene in cancer. TGF $\beta 1$ is associated with poor prognosis of esophageal cancer (85). TGF $\beta 1$-mediated downregulation of E-cadherin contributes to tumor invasion and proliferation. Overexpression of Rac3 attenuated TGF $\beta 1$-induced EC cell line
OE19 elongation phenotype. Inhibition of Rac3 by FBXL19 attenuated the TGF $\beta 1$-induced decrease of E-cadherin in EC cell lines OE19 and OE33 (86). RhoA is a new substrate for FBXL19. RhoA phosphorylation by Erk2 promotes FBXL19mediated RhoA degradation, since inhibition of the Erk pathway attenuates RhoA ubiquitination, while overexpression of Erk2 reduces RhoA stability. RhoA plays a critical role in regulation of cell growth and cytoskeleton rearrangement (87). ERK2 is a serine/threonine kinase involved in numerous cellular pathways, including growth and development, and ERK phosphorylation is triggered by activation of receptor tyrosine kinases in response to growth factor signals (88).

FBXO4. Cyclin-dependent kinases (CDK) drive cell-cycle progression, control transcriptional processes, and thus, regulate cell proliferation. Cyclin D1, the allosteric regulator of CDK4/6, is an integral mediator of growth factor-dependent G1 phase progression. Cyclin D1 overexpression occurs frequently in human cancer including esophageal carcinomas. Both CDK4 and CDK6, when complexed with cyclin D1, promote cell cycle progression (89). FBXO4 is an F-box constituent of SCF ubiquitin ligases that directs ubiquitylation of cyclin D1 (90), therefore, FBXO4 was considered as a tumor suppressor. FBXO4 promotes the ubiquitination and degradation of TRF1, which is important for maintaining telomere length. This role might make FBXO4 a factor in extending the lifespan of nascent transforming cells (91). A study from Barbash et al detected 14\% hemizygous, missense mutations in the primary human esophageal carcinoma (92). FBXO4 loss predisposes mice to NMBA (an esophageal carcinogen) induced papilloma formation, which could be reversed by CDK4/6 inhibitors. This results comfirmed the suppressor role of FBXO4 and FBXO4/cyclin D1 pathway in esophageal tumorigenesis (91).

FBPs as oncogenes in EC. FBXO31. FBXO31 is a candidate breast tumor suppressor encoded in 16q24.3 and plays a crucial role in DNA damage response $(93,94)$. The expression and function of FBXO31 is controversial in different type of cancers. Studies in breast cancer (95), hepatocellular carcinoma (96) and gastric cancer (97) indicated that FBXO31 functioned as a tumor suppressor. FBXO31 mediated-degradation of MDM2 increased the levels of p53 and led to growth arrest, suggesting FBXO31 as a tumor suppressor (98). Recently, a study showed a conflicting result in lung cancer (99). Higher expression of FBXO31 significantly correlated to tumor size and infiltration, clinical stages and metastasis. In addition, exogenous expression of FBXO31 promoted cell growth, metastasis and invasion in lung cancer cell line A549. Moreover, tumorigenicity assays in nude mice showed FBXO31 promoted tumor growth in vivo. This result was consistent with the report by Kogo et al (100). They demonstrated the expression of FBXO31 in 68 ESCC cases. High expression of FBXO31 was related to depth of tumor invasion and clinical stage, but showed no significant differences in lymph node metastasis, lymphatic and venous invasion. Furthermore, FBXO31 mRNA expression in ESCC cancer tissue may be promising novel prognostic marker. The previously identified substrate for $\mathrm{SCF}^{\mathrm{Fbx} 031}$ in melanoma cells is Cyclin D1 (93). However, in ESCC cancer cells, FBXO31 mediates MKK6 but not cyclin D1 for degradation, 


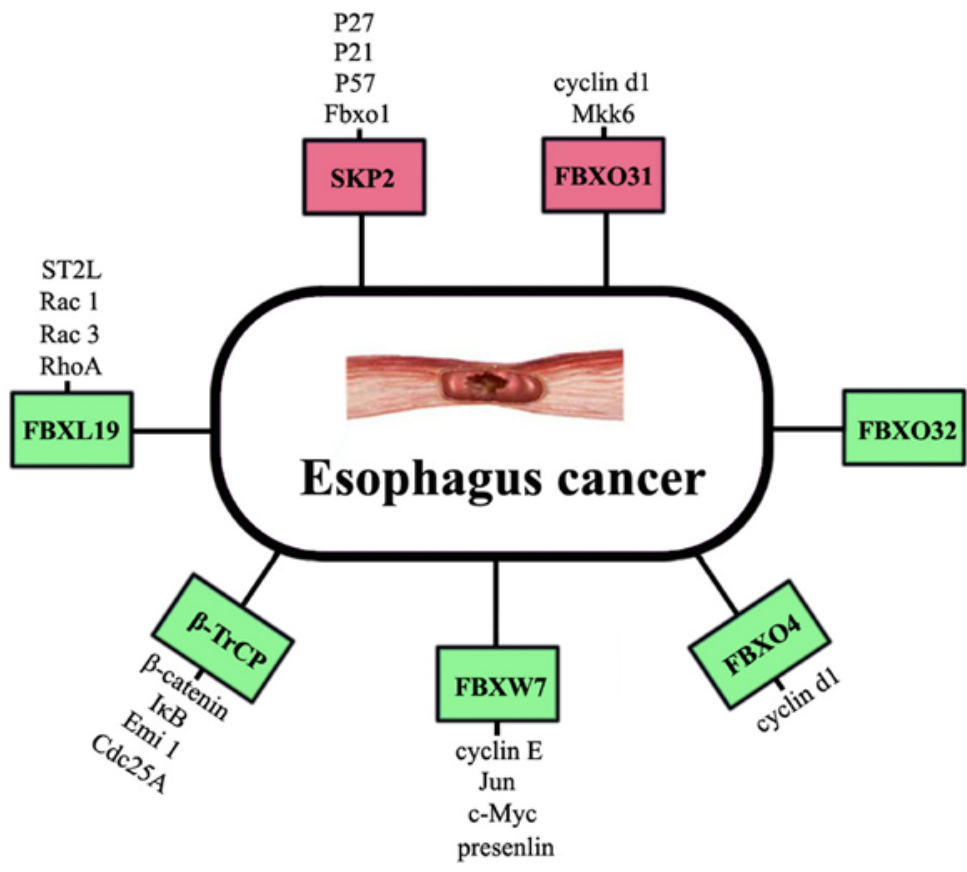

Figure 3. Main FBPs and their major downstream targets in EC. SKP2 and FBXO31 are potential oncogenes in EC (in the red background). FBXW7, $\beta$-TrCP, FBXL19, FBXO4 and FBXO32 are potential downstream suppressor genes in EC (in the green background).

and FBXO31 exerts anti-apoptotic effects on cancer cells in response to stress stimuli (94).

\section{Conclusion and future direction}

Extensive study of UPS has led to a better understanding of the molecular mechanism by which E3 ligases contribute to EC. FBPs are the core components of PBPs. Two F-box proteins SKP2 and FBXW7 have showed strong clinical relevance in the initiation and development of EC. Other FBPs such as $\beta$-TrCP, FBXL19, FBXO4, FBXO31 and FBXO32 have been proved to be involved in EC (Fig. 3) (101). Considering that F-box proteins can bind with a diversity of substrates and that each substrate may be regulated by many different E3 ligases depending on cell type. Therefore, identifying critical substrates of each F-box protein is paramount for understanding tumorigenesis and discovering therapeutic targets. However, it should be stressed that FBPs deregulate an entire network of proteins. Two main substrates of $\beta$-TrCP are $\mathrm{I} \kappa \mathrm{B}$ in the $\mathrm{NF}-\kappa \mathrm{B}$ pathway and $\beta$-catenin in Wnt pathway $(71,72)$. I $\kappa \mathrm{B}$, inhibitor of $\mathrm{NF}-\kappa \mathrm{B}$, functions as a tumor suppressor. $\beta$-catenin has been identified to be an oncogene in cancers. Intriguingly, some FBPs can be controlled by their substrates. More complicated substrates feed back to control FBPs. FBXW7 $\alpha$ interacts with C/EBPס and targets it for degradation (62), but C/EBPס inhibits FBXW7 expression and promotes mammary tumour metastasis (102). Consistent with these findings is a recent study by Sancho and colleagues which show that, FBXW7 repression by hes5 (a Notch target gene) creates a feedback loop that modulates Notch-mediated intestinal and neural stem cell fate decisions (103).

In conclusion, this review provides only a glimpse into the mechanisms through which FBPs are involved in EC. However, all the current understanding is just the tip of the iceberg. The growing details in understanding of SCF-based protein targeting of a diverse array of fundamental substrates provide a great opportunity for cancer therapeutic development targeting FBPs. It has become clear that some FBPs, such as SKP2 and FBXW7, are promising targets for EC therapy. The proteasome inhibitor bortezomib, which blocks the entire protein degradation, highlighted the therapeutic potential of targeting this protein degradation system (104). However, bortezomib has been used in clinical trial for cancer treatment but with limited success. Selective inhibitors targeting a particular E3 ligase or a certain F-box protein may be more effective, but extensive research is to be continued (105). To this end, there are still many important remaining questions to be resolved. We need to identify the physiological substrates for many orphan F-box proteins. To assess whether there is crosstalk between individual F-box proteins calls for research in this emerging area involving functional delineation of FBPs and their cellular context-specific substrates in human EC. A better mechanistic understanding of FBP-regulated network of proteins in initiation and progression of cancer will be a research hotpot in the future.

\section{Acknowledgements}

J.G. and J.-R.H. are grateful for the Fundamental Research Funds from the Central Universities of Central South University (no. 2015zzts119).

\section{References}

1. Jemal A, Bray F, Center MM, Ferlay J, Ward E and Forman D: Global cancer statistics. CA Cancer J Clin 61: 69-90, 2011.

2. Pennathur A, Gibson MK, Jobe BA and Luketich JD: Oesophageal carcinoma. Lancet 381: 400-412, 2013.

3. Gammon MD, Schoenberg JB, Ahsan H, Risch HA, Vaughan TL, Chow WH, Rotterdam H, West AB, Dubrow R, Stanford JL, et al: Tobacco, alcohol, and socioeconomic status and adenocarcinomas of the esophagus and gastric cardia. J Natl Cancer Inst 89: 1277-1284, 1997 . 
4. Tang WR, Fang JY, Wu KS, Shi XJ, Luo JY and Lin K: Epidemiological characteristics and prediction of esophageal cancer mortality in China from 1991 to 2012. Asian Pac J Cancer Prev 15: 6929-6934, 2014.

5. Enzinger PC and Mayer RJ: Esophageal cancer. N Engl J Med 349: 2241-2252, 2003.

6. Hanahan D and Weinberg RA: The hallmarks of cancer. Cell 100: 57-70, 2000.

7. Hershko DD: Oncogenic properties and prognostic implications of the ubiquitin ligase Skp2 in cancer. Cancer 112: 1415-1424, 2008

8. Gao M and Karin M: Regulating the regulators: Control of protein ubiquitination and ubiquitin-like modifications by extracellular stimuli. Mol Cell 19: 581-593, 2005.

9. Thrower JS, Hoffman L, Rechsteiner M and Pickart CM: Recognition of the polyubiquitin proteolytic signal. EMBO J 19 94-102, 2000.

10. Kitagawa K, Kotake Y and Kitagawa M: Ubiquitin-mediated control of oncogene and tumor suppressor gene products. Cancer Sci 100: 1374-1381, 2009

11. Zhao Y and Sun Y: Cullin-RING Ligases as attractive anticancer targets. Curr Pharm Des 19: 3215-3225, 2013.

12. Reed SI: Ratchets and clocks: The cell cycle, ubiquitylation and protein turnover. Nat Rev Mol Cell Biol 4: 855-864, 2003.

13. Peters J-M: The anaphase promoting complex/cyclosome: A machine designed to destroy. Nat Rev Mol Cell Biol 7: 644-656, 2006

14. Wang Z, Liu P, Inuzuka $\mathrm{H}$ and Wei W: Roles of F-box proteins in cancer. Nat Rev Cancer 14: 233-247, 2014.

15. Lockwood WW, Chandel SK, Stewart GL, ErdjumentBromage $\mathrm{H}$ and Beverly LJ: The novel ubiquitin ligase complex $\mathrm{SCF}(\mathrm{Fbxw} 4)$, interacts with the COP9 signalosome in an F-box dependent manner, is mutated, lost and under-expressed in human cancers. PLoS One 8: e63610, 2013.

16. Huber C, Dias-Santagata D, Glaser A, O'Sullivan J, Brauner R, Wu K, Xu X, Pearce K, Wang R, Uzielli ML, et al: Identification of mutations in CUL7 in 3-M syndrome. Nat Genet 37: 1119-1124, 2005 .

17. Tzatsos A, Paskaleva P, Ferrari F, Deshpande V, Stoykova S, Contino G, Wong KK, Lan F, Trojer P, Park PJ, et al: KDM2B promotes pancreatic cancer via Polycomb-dependent and -independent transcriptional programs. J Clin Invest 123: 727-739, 2013.

18. Wu W, Ding H, Cao J and Zhang W: FBXL5 inhibits metastasis of gastric cancer through suppressing Snail1. Cell Physiol Biochem 35: 1764-1772, 2015.

19. Cardozo T and Pagano M: The SCF ubiquitin ligase: Insights into a molecular machine. Nat Rev Mol Cell Biol 5: 739-751, 2004.

20. Zhao Y, Tang Q, Ni R, Huang X, Wang Y, Lu C, Shen A, Wang Y, Li C, Yuan Q, et al: Early mitotic inhibitor-1, an anaphasepromoting complex/cyclosome inhibitor, can control tumor cell proliferation in hepatocellular carcinoma: Correlation with Skp2 stability and degradation of p27(Kip1). Hum Pathol 44: 365-373, 2013.

21. Duan S, Cermak L, Pagan JK, Rossi M, Martinengo C, di Celle PF, Chapuy B, Shipp M, Chiarle R and Pagano M: FBXO11 targets BCL6 for degradation and is inactivated in diffuse large B-cel lymphomas. Nature 481: 90-93, 2012.

22. Demetrick DJ, Zhang H and Beach DH: Chromosomal mapping of the genes for the human CDK2/cyclin A-associated proteins p19 (SKP1A and SKP1B) and p45 (SKP2). Cytogenet Cell Genet 73: 104-107, 1996.

23. Hershko D, Bornstein G, Ben-Izhak O, Carrano A, Pagano M, Krausz MM and Hershko A: Inverse relation between levels of p27(Kip1) and of its ubiquitin ligase subunit Skp2 in colorectal carcinomas. Cancer 91: 1745-1751, 2001.

24. Fukuchi M, Masuda N, Nakajima M, Fukai Y, Miyazaki T, Kato $\mathrm{H}$ and Kuwano $\mathrm{H}$ : Inverse correlation between expression levels of p27 and the ubiquitin ligase subunit Skp2 in early esophageal squamous cell carcinoma. Anticancer Res 24 (2B): 777-783, 2004

25. Yang G, Ayala G, De Marzo A, Tian W, Frolov A, Wheeler TM, Thompson TC and Harper JW: Elevated Skp2 protein expression in human prostate cancer: Association with loss of the cyclindependent kinase inhibitor p27 and PTEN and with reduced recurrence-free survival. Clin Cancer Res 8: 3419-3426, 2002.

26. Traub F, Mengel M, Lück HJ, Kreipe HH and von Wasielewski R Prognostic impact of Skp2 and p27 in human breast cancer. Breast Cancer Res Treat 99: 185-191, 2006.
27. Masuda TA, Inoue H, Sonoda H, Mine S, Yoshikawa Y, Nakayama K, Nakayama K and Mori M: Clinical and biological significance of S-phase kinase-associated protein 2 (Skp2) gene expression in gastric carcinoma: Modulation of malignant phenotype by Skp2 overexpression, possibly via p27 proteolysis. Cancer Res 62: 3819-3825, 2002.

28. Frescas D and Pagano M: Deregulated proteolysis by the F-box proteins SKP2 and beta-TrCP: Tipping the scales of cancer. Nat Rev Cancer 8: 438-449, 2008.

29. Rose AE, Wang G, Hanniford D, Monni S, Tu T, Shapiro RL, Berman RS, Pavlick AC, Pagano M, Darvishian F, et al: Clinical relevance of SKP2 alterations in metastatic melanoma. Pigment Cell Melanoma Res 24: 197-206, 2011.

30. Xu HM, Liang Y, Chen Q, Wu QN, Guo YM, Shen GP, Zhang RH, He ZW, Zeng YX, Xie FY, et al: Correlation of Skp2 overexpression to prognosis of patients with nasopharyngeal carcinoma from South China. Chin J Cancer 30: 204-212, 2011.

31. Schüler S, Diersch S, Hamacher R, Schmid RM, Saur D and Schneider G: SKP2 confers resistance of pancreatic cancer cells towards TRAIL-induced apoptosis. Int J Oncol 38: 219-225, 2011

32. Wang Z, Fukushima H, Inuzuka H, Wan L, Liu P, Gao D, Sarkar FH and Wei W: Skp2 is a promising therapeutic target in breast cancer. Front Oncol 1: 18702, 2012

33. Shapira M, Ben-Izhak O, Linn S, Futerman B, Minkov I and Hershko DD: The prognostic impact of the ubiquitin ligase subunits Skp2 and Cks1 in colorectal carcinoma. Cancer 103. $1336-1346,2005$

34. Wang XC, Wu YP, Ye B, Lin DC, Feng YB, Zhang ZQ, Xu X, Han YL, Cai Y, Dong JT, et al: Suppression of anoikis by SKP2 amplification and overexpression promotes metastasis of esophageal squamous cell carcinoma. Mol Cancer Res 7: 12-22, 2009.

35. Yokoi S, Yasui K, Saito-Ohara F, Koshikawa K, Iizasa T, Fujisawa T, Terasaki T, Horii A, Takahashi T, Hirohashi S, et al: A novel target gene, SKP2, within the $5 \mathrm{p} 13$ amplicon that is frequently detected in small cell lung cancers. Am J Pathol 161: 207-216, 2002

36. Wang XC, Tian LL, Tian J and Jiang XY: Overexpression of SKP2 promotes the radiation resistance of esophageal squamous cell carcinoma. Radiat Res 177: 52-58, 2012.

37. Bai P, Xiao X, Zou J, Cui L, Bui Nguyen TM, Liu J, Xiao J, Chang B, Wu J and Wang H: Expression of p14(ARF), p15(INK4b), p16(INK4a) and skp2 increases during esophageal squamous cell cancer progression. Exp Ther Med 3: 1026-1032, 2012.

38. Liang Y, Hou X, Cui Q, Kang T-B, Fu J-H, Zhang L-J, Luo R-Z, He J-H, Zeng Y-X and Yang H-X: Skp2 expression unfavorably impacts survival in resectable esophageal squamous cell carcinoma. J Transl Med 10: 73, 2012.

39. Hennessy BT, Smith DL, Ram PT, Lu Y and Mills GB: Exploiting the PI3K/AKT pathway for cancer drug discovery. Nat Rev Drug Discov 4: 988-1004, 2005

40. Gao D, Inuzuka H, Tseng A, Chin RY, Toker A and Wei W: Phosphorylation by Akt1 promotes cytoplasmic localization of Skp2 and impairs APCCdh1-mediated Skp2 destruction. Nat Cell Biol 11: 397-408, 2009.

41. van Duijn PW and Trapman J: PI3K/Akt signaling regulates p27(kip1) expression via Skp2 in PC3 and DU145 prostate cancer cells, but is not a major factor in $\mathrm{p} 27(\mathrm{kip} 1)$ regulation in $\mathrm{LNCaP}$ and PC346 cells. Prostate 66: 749-760, 2006.

42. Reichert M, Saur D, Hamacher R, Schmid RM and Schneider G: Phosphoinositide-3-kinase signaling controls S-phase kinaseassociated protein 2 transcription via E2F1 in pancreatic ductal adenocarcinoma cells. Cancer Res 67: 4149-4156, 2007.

43. Nakayama KI and Nakayama K: Ubiquitin ligases: Cell-cycle control and cancer. Nat Rev Cancer 6: 369-381, 2006.

44. Andreu EJ, Lledó E, Poch E, Ivorra C, Albero MP, MartínezCliment JA, Montiel-Duarte C, Rifón J, Pérez-Calvo J, Arbona C, et al: BCR-ABL induces the expression of Skp2 through the PI3K pathway to promote $\mathrm{p} 27 \mathrm{Kip} 1$ degradation and proliferation of chronic myelogenous leukemia cells. Cancer Res 65: 3264$3272,2005$.

45. Hartwell LH, Mortimer RK, Culotti J and Culotti M: Genetic Control of the Cell Division Cycle in Yeast: V. Genetic Analysis of cdc Mutants. Genetics 74: 267-286, 1973.

46. Sionov RV, Netzer E and Shaulian E: Differential regulation of FBXW7 isoforms by various stress stimuli. Cell Cycle 12: 3547-3554, 2013. 
47. Davis RJ, Welcker M and Clurman BE: Tumor suppression by the Fbw7 ubiquitin ligase: Mechanisms and opportunities. Cancer Cell 26: 455-464, 2014

48. Minella AC, Welcker M and Clurman BE: Ras activity regulates cyclin E degradation by the Fbw7 pathway. Proc Natl Acad Sci USA 102: 9649-9654, 2005.

49. Yada M: Hat ediated by the F-box protein Fbw7. EMBO J 23: 2116-2125, 2004.

50. Hoeck JD, Jandke A, Blake SM, Nye E, Spencer-Dene B, Brandner S and Behrens A: Fbw7 controls neural stem cell differentiation and progenitor apoptosis via Notch and c-Jun. Nat Neurosci 13: 1365-1372, 2010.

51. Enkhbold C, Utsunomiya T, Morine Y, Imura S, Ikemoto T, Arakawa Y, Kanamoto M, Iwahashi S, Saito Y, Ishikawa D, et al: Loss of FBXW7 expression is associated with poor prognosis in intrahepatic cholangiocarcinoma. Hepatol Res 44: E346-E352, 2014.

52. Ibusuki M, Yamamoto Y, Shinriki S, Ando Y and Iwase H: Reduced expression of ubiquitin ligase FBXW7 mRNA is associated with poor prognosis in breast cancer patients. Cancer Sci 102: 439-445, 2011.

53. Iwatsuki M, Mimori $\mathrm{K}$, Ishii $\mathrm{H}$, Yokobori $\mathrm{T}$, Takatsuno $\mathrm{Y}$, Sato T, Toh H, Onoyama I, Nakayama KI, Baba H, et al: Loss of FBXW7, a cell cycle regulating gene, in colorectal cancer: Clinical significance. Int J Cancer 126: 1828-1837, 2010.

54. Kurashige J, Watanabe M, Iwatsuki M, Kinoshita K, Saito S, Hiyoshi Y, Kamohara H, Baba Y, Mimori K and Baba $\mathrm{H}$ : Overexpression of microRNA-223 regulates the ubiquitin ligase FBXW7 in oesophageal squamous cell carcinoma. Br J Cancer 106: 182-188, 2012.

55. Yokobori T, Mimori K, Iwatsuki M, Ishii H, Onoyama I, Fukagawa T, Kuwano H, Nakayama KI and Mori M: p53-altered FBXW7 expression determines poor prognosis in gastric cancer cases. Cancer Res 69: 3788-3794, 2009.

56. Kimura T, Gotoh M, Nakamura Y and Arakawa H: hCDC4b, a regulator of cyclin $\mathrm{E}$, as a direct transcriptional target of $\mathrm{p} 53$. Cancer Sci 94: 431-436, 2003.

57. Inuzuka H, Shaik S, Onoyama I, Gao D, Tseng A, Maser RS, Zhai B, Wan L, Gutierrez A, Lau AW, et al: SCF(FBW7) regulates cellular apoptosis by targeting MCL1 for ubiquitylation and destruction. Nature 471: 104-109, 2011.

58. Wertz IE, Kusam S, Lam C, Okamoto T, Sandoval W, Anderson DJ, Helgason E, Ernst JA, Eby M, Liu J, et al: Sensitivity to antitubulin chemotherapeutics is regulated by MCL1 and FBW7. Nature 471: 110-114, 2011.

59. Chen J, Shin JH, Zhao R, Phan L, Wang H, Xue Y, Post SM, Ho Choi H, Chen JS, Wang E, et al: CSN6 drives carcinogenesis by positively regulating Myc stability. Nat Commun 5: 5384, 2014.

60. Ji S, Qin Y, Shi S, Liu X, Hu H, Zhou H, Gao J, Zhang B, Xu W, Liu J, et al: ERK kinase phosphorylates and destabilizes the tumor suppressor FBW7 in pancreatic cancer. Cell Res 25: $561-573,2015$.

61. Sterian A, Kan T, Berki AT, Mori Y, Olaru A, Schulmann K, Sato F, Wang S, Paun B, Cai K, et al: Mutational and LOH analyses of the chromosome $4 \mathrm{q}$ region in esophageal adenocarcinoma. Oncology 70: 168-172, 2006.

62. Balamurugan K, Sharan S, Klarmann KD, Zhang Y, Coppola V, Summers GH, Roger T, Morrison DK, Keller JR and Sterneck E: FBXW7 $\alpha$ attenuates inflammatory signalling by downregulating C/EBPS and its target gene Tlr4. Nat Commun 4: 1662, 2013.

63. Yokobori T, Mimori K, Iwatsuki M, Ishii H, Tanaka F, Sato T, Toh H, Sudo T, Iwaya T, Tanaka Y, et al: Copy number loss of FBXW7 is related to gene expression and poor prognosis in esophageal squamous cell carcinoma. Int J Oncol 41: 253-259, 2012.

64. Xu Y, Sengupta T, Kukreja L and Minella AC: MicroRNA-223 regulates cyclin $\mathrm{E}$ activity by modulating expression of F-box and WD-40 domain protein 7. J Biol Chem 285: 34439-34446, 2010.

65. Gomes MD, Lecker SH, Jagoe RT, Navon A and Goldberg AL: Atrogin-1, a muscle-specific F-box protein highly expressed during muscle atrophy. Proc Natl Acad Sci USA 98: 14440-14445, 2001.

66. Hanai J, Cao P, Tanksale P, Imamura S, Koshimizu E, Zhao J, Kishi S, Yamashita M, Phillips PS, Sukhatme VP, et al: The muscle-specific ubiquitin ligase atrogin-1/MAFbx mediates statin-induced muscle toxicity. J Clin Invest 117: 3940-3951, 2007.
67. Guo W, Zhang M, Shen S, Guo Y, Kuang G, Yang Z and Dong Z: Aberrant methylation and decreased expression of the TGF- $\beta$ /Smad target gene FBXO32 in esophageal squamous cell carcinoma. Cancer 120: 2412-2423, 2014.

68. Guo W, Zhang M, Guo Y, Shen S, Guo X and Dong Z: FBXO32, a new TGF- $\beta /$ Smad signaling pathway target gene, is epigenetically inactivated in gastric cardia adenocarcinoma. Neoplasma 62: 646-657, 2015.

69. Chou JL, Su HY, Chen LY, Liao YP, Hartman-Frey C, Lai YH, Yang HW, Deatherage DE, Kuo CT, Huang YW, et al: Promoter hypermethylation of FBXO32, a novel TGF-beta/SMAD4 target gene and tumor suppressor, is associated with poor prognosis in human ovarian cancer. Lab Invest 90: 414-425, 2010.

70. Wu Y, Deng J, Rychahou PG, Qiu S, Evers BM and Zhou BP: Stabilization of snail by NF-kappaB is required for inflammationinduced cell migration and invasion. Cancer Cell 15: 416-428, 2009.

71. Shirane M, Hatakeyama S, Hattori K, Nakayama K and Nakayama K: Common pathway for the ubiquitination of IkappaBalpha, IkappaBbeta, and IkappaBepsilon mediated by the F-box protein FWD1. J Biol Chem 274: 28169-28174, 1999.

72. Spiegelman VS, Slaga TJ, Pagano M, Minamoto T, Ronai $Z$ and Fuchs SY: Wnt/beta-catenin signaling induces the expression and activity of betaTrCP ubiquitin ligase receptor. Mol Cell 5: 877-882, 2000.

73. Zhang N, Wei P, Gong A, Chiu WT, Lee HT, Colman H, Huang H, Xue J, Liu M, Wang Y, et al: FoxM1 promotes $\beta$-catenin nuclear localization and controls Wnt target-gene expression and glioma tumorigenesis. Cancer Cell 20: 427-442, 2011.

74. Mokkapati S, Niopek K, Huang L, Cunniff KJ, Ruteshouser EC, deCaestecker M, Finegold MJ and Huff V: $\beta$-catenin activation in a novel liver progenitor cell type is sufficient to cause hepatocellular carcinoma and hepatoblastoma. Cancer Res 74: 4515-4525, 2014

75. Li AF, Hsu PK, Tzao C, Wang YC, Hung IC, Huang MH and Hsu HS: Reduced axin protein expression is associated with a poor prognosis in patients with squamous cell carcinoma of esophagus. Ann Surg Oncol 16: 2486-2493, 2009.

76. Katoh $\mathrm{M}$ and Katoh M: Identification and characterization of FBXL19 gene in silico. Int J Mol Med 14: 1109-1114, 2004.

77. O'Rielly DD and Rahman P: Genetics of psoriatic arthritis. Best Pract Res Clin Rheumatol 28: 673-685, 2014.

78. Chandran V: The genetics of psoriasis and psoriatic arthritis. Clin Rev Allergy Immunol 44: 149-156, 2013.

79. Cabaleiro T, Prieto-Pérez R, Navarro R, Solano G, Román M, Ochoa D, Abad-Santos F and Daudén E: Paradoxical psoriasiform reactions to anti-TNFo drugs are associated with genetic polymorphisms in patients with psoriasis. Pharmacogenomics $\mathrm{J}$ : Jul 21, 2015 (Epub ahead of print). http://dx.doi.org/10.1038/ tpj.2015.53.

80. Kurowska-Stolarska M, Hueber A, Stolarski B and McInnes IB: Interleukin-33: A novel mediator with a role in distinct disease pathologies. J Intern Med 269: 29-35, 2011.

81. Zhao J, Wei J, Mialki RK, Mallampalli DF, Chen BB, Coon T, Zou C, Mallampalli RK and Zhao Y: F-box protein FBXL19mediated ubiquitination and degradation of the receptor for IL-33 limits pulmonary inflammation. Nat Immunol 13: 651-658, 2012

82. Zhao J, Mialki RK, Wei J, Coon TA, Zou C, Chen BB, Mallampalli RK, Zhao Y: SCF E3 ligase F-box protein complex SCF (FBXL19) regulates cell migration by mediating Racl ubiquitination and degradation. FASEB J 27: 2611-2619, 2013.

83. ten Klooster JP, Leeuwen I, Scheres N, Anthony EC and Hordijk PL: Rac1-induced cell migration requires membrane recruitment of the nuclear oncogene SET. EMBO J 26: 336-345, 2007.

84. Su J and Li H: RAC1 overexpression promotes the proliferation, migration and epithelial-mesenchymal transition of lens epithelial cells. Int J Clin Exp Pathol 8: 10760-11767, 2015.

85. Filippi MD, Szczur K, Harris CE and Berclaz PY: Rho GTPase Racl is critical for neutrophil migration into the lung. Blood 109: 1257-1264, 2007.

86. Lao-Sirieix P and Fitzgerald RC: Role of the micro-environment in Barrett's carcinogenesis. Biochem Soc Trans 38: 327-330, 2010.

87. Dong S, Zhao J, Wei J, Bowser RK, Khoo A, Liu Z, Luketich JD, Pennathur A, Ma H and Zhao Y: F-box protein complex FBXL19 regulates TGF $\beta 1$-induced E-cadherin down-regulation by mediating Rac3 ubiquitination and degradation. Mol Cancer 13: 76, 2014. 
88. Wei J, Mialki RK, Dong S, Khoo A, Mallampalli RK, Zhao Y, and Zhao J: A new mechanism of RhoA ubiquitination and degradation: roles of SCF(FBXL19) E3 ligase and Erk2. Biochim Biophys Acta 1833: 2757-2764, 2013.

89. Sheppard KE and McArthur GA: The cell-cycle regulator CDK4: An emerging therapeutic target in melanoma. Clin Cancer Res 19: 5320-5328, 2013.

90. Lian Z, Lee EK, Bass AJ, Wong KK, Klein-Szanto AJ, Rustgi AK, Diehl JA: FBXO4 loss facilitates carcinogen induced papilloma development in mice. Cancer Biol Ther 16 750-755, 2015.

91. Lee TH, Perrem K, Harper JW, Lu KP and Zhou XZ: The F-box protein FBX4 targets PIN2/TRF1 for ubiquitin-mediated degradation and regulates telomere maintenance. J Biol Chem 281: 759-768, 2006.

92. Barbash O, Zamfirova P, Lin DI, Chen X, Yang K, Nakagawa H, Lu F, Rustgi AK and Diehl JA: Mutations in Fbx4 inhibit dimerization of the $\mathrm{SCF}(\mathrm{Fbx} 4)$ ligase and contribute to cyclin D1 overexpression in human cancer. Cancer Cell 14: 68-78, 2008.

93. Santra MK, Wajapeyee N and Green MR: F-box protein FBXO31 mediates cyclin D1 degradation to induce G1 arrest after DNA damage. Nature 459: 722-725, 2009.

94. Jia L and Sun Y: F-box proteins FBXO31 and FBX4 in regulation of cyclin D1 degradation upon DNA damage. Pigment Cell Melanoma Res 22: 518-519, 2009.

95. Kumar R, Neilsen PM, Crawford J, McKirdy R, Lee J, Powell JA, Saif Z, Martin JM, Lombaerts M, Cornelisse CJ, et al: FBXO31 is the chromosome $16 \mathrm{q} 24.3$ senescence gene, a candidate breast tumor suppressor, and a component of an SCF complex. Cancer Res 65: 11304-11313, 2005.

96. Huang HL, Zheng WL, Zhao R, Zhang B and Ma WL: FBXO31 is down-regulated and may function as a tumor suppressor in hepatocellular carcinoma. Oncol Rep 24: 715-720, 2010.
97.Zhang X, Kong Y, Xu X, Xing H, Zhang Y, Han F, Li W, Yang Q, Zeng J, Jia J, et al: F-box protein FBXO31 is down-regulated in gastric cancer and negatively regulated by $\mathrm{miR}-17$ and miR-20a. Oncotarget 5: 6178-6190, 2014.

98. Malonia SK, Dutta P, Santra MK and Green MR: F-box protein FBXO31 directs degradation of MDM2 to facilitate p53-mediated growth arrest following genotoxic stress. Proc Natl Acad Sci USA 112: 8632-8637, 2015.

99. Huang HL, Jiang Y, Wang YH, Chen T, He HJ, Liu T, Yang T, Yang LW, Chen J, Song ZQ, et al: FBXO31 promotes cell proliferation, metastasis and invasion in lung cancer. Am J Cancer Res 5: 1814-1822, 2015.

100. Kogo R, Mimori K, Tanaka F, Komune S and Mori M: FBXO31 determines poor prognosis in esophageal squamous cell carcinoma. Int J Oncol 39: 155-159, 2011

101. Liu J, Han L, Li B, Yang J, Huen MS, Pan X, Tsao SW and Cheung AL: F-box only protein 31 (FBXO31) negatively regulates p38 mitogen-activated protein kinase (MAPK) signaling by mediating lysine 48-linked ubiquitination and degradation of mitogen-activated protein kinase kinase 6 (MKK6). J Biol Chem 289: 21508-21518, 2014.

102. Balamurugan K, Wang JM, Tsai HH, Sharan S, Anver M, Leighty R and Sterneck E: The tumour suppressor C/EBPd inhibits FBXW7 expression and promotes mammary tumour metastasis. EMBO J 29: 4106-4117, 2010.

103. Sancho R, Blake SM, Tendeng C, Clurman BE, Lewis J and Behrens A: Fbw7 repression by hes5 creates a feedback loop that modulates Notch-mediated intestinal and neural stem cell fate decisions. PLoS Biol 11: e1001586, 2013.

104. Kane RC, Bross PF, Farrell AT and Pazdur R: Velcade: U.S. FDA approval for the treatment of multiple myeloma progressing on prior therapy. Oncologist 8: 508-513, 2003.

105. Skaar JR, Pagan JK and Pagano M: SCF ubiquitin ligasetargeted therapies. Nat Rev Drug Discov 13: 889-903, 2014. 